\title{
Environmentally benign processing of YAG transparent wafers
}

Yan Yang and Yiquan $\mathrm{Wu}^{*}$

Kazuo Inamori School of Engineering, New York State College of Ceramics, Alfred University, Alfred, New York, 14802, USA

* Corresponding author: E-mail: wuy@alfred.edu; Tel: +1-607-871-2662; Fax: +1-607-871-2354

\begin{abstract}
:
Transparent yttrium aluminum garnet (YAG) wafers were successfully produced via aqueous tape casting and vacuum sintering techniques using a new environmentally friendly binder, a copolymer of isobutylene and maleic anhydride with the commercial name ISOBAM (noted as ISOBAM). Aqueous YAG slurries were mixed by ball-milling, which was followed by de-gassing and tape casting of wafers. The final YAG green tapes were homogenous and flexible, and could be bent freely without cracking. After the drying and sintering processes, transparent YAG wafers were achieved. The microstructures of both the green tape and vacuum-sintered YAG ceramic were observed by scanning electronic microscopy (SEM). Phase compositions were examined by X-ray diffraction (XRD). Optical transmittance was measured in UV-VIS regions with the result that the transmittance is $82.6 \%$ at a wavelength of $800 \mathrm{~nm}$.
\end{abstract}

Keywords: transparent, ceramic wafer, yttrium aluminum garnet, tape casting, rheological property

\section{Introduction}

With the increasing use of flat, thin and large scale ceramics for fabrication of substrates, packaging and multilayer technology[1-3] (capacitors[4], sensors[5], piezoactuator[6], laser composites[7], etc.), tape casting techniques have been very widely preferred over conventional ceramic processing techniques such as dry pressing, slip casting, and gel casting. Flat ceramic wafers with thicknesses ranging from a few microns to a few millimeters can be produced precisely by tape casting techniques.

Traditionally, tape casting is performed using organic solvents as liquid medium [4, 7-13], taking advantage of low boiling point, easy evaporation during the drying step, good wetting properties and 
inertness to ceramic powders. However, due to environmental and health considerations, as well as high flammability and volatility of organic solvents, coupled with their high production cost, more research on water-based systems has developed in recent years. However, water-based systems are more sensitive than organic solvent systems to processing parameters, such as casting composition, drying conditions, and film thickness[14]. Issues such as the required use of slower drying rates, easy foaming and premature polymerization[15], require that more work on the aqueous tape casting techniques be done.

The typical tape casting system consists of well-dispersed suspension with water soluble dispersant, binder and plasticizer. During the tape casting process, particle size distribution, dispersion stability, and sedimentation play important roles on the quality of the final product in terms of the presence of cracks and deformation[16, 17]. Dispersant must be added to prevent micron/submicron size ceramic powders from agglomerating, a result of powders' electrostatic forces and high surface area/mass ratio[18]. Moreover, many binders have been evaluated for aqueous tape casting techniques, such as acrylic polymers[19, 20], cellulose ethers[21, 22], polyvinyl alcohols [23], latex emulsions[24], gelatin[25], etc. Interestingly, Reddy et al. reported the dispersant effect of binders in tape cast slurries[26, 27], which indicated the possibility of simplifying the tape casting process by removing the necessity of dispersant. ISOBAM is one binder which has been recently reported as a spontaneous gelling agent which also acts as an effective dispersant in aqueous systems [28-33].

ISOBAM is a water soluble copolymer (M.W. = 160 000 300 000) of isobutylene and maleic anhydride, with the appearance of white powder, density $1.3 \mathrm{~g} / \mathrm{cm}^{3}$; which has application as a binder for ceramic processing techniques. In this work ISOBAM was adopted as both binder and dispersant for aqueous tape casting processes. After the ball milling and de-gassing processes, the slurry was casted on a plastic carrier. After debinding and vacuum sintering, transparent yttrium aluminum garnet (YAG) chips were finally achieved.

\section{Experimental}




\subsection{YAG slurries preparation}

High-purity powders of $\alpha-\mathrm{Al}_{2} \mathrm{O}_{3}$ (Baikowski, Annecy, France), $\mathrm{Y}_{2} \mathrm{O}_{3}$ (99.99\%, Sigma-Aldrich Corp, USA), and ISOBAM (Kuraray, Japan) were used as raw materials.

YAG slurries with solids loading of $63.5 \mathrm{wt} \%$ were mixed by ball-milling with zirconia grinding media at a speed of 200-300 rpm for 3 hours. After the addition of plasticizer, the slurry was casted on a stationary Mylar carrier with a moving doctor blade at a speed of $10-35 \mathrm{~cm} / \mathrm{min}$. After drying in air for 24 hours at room temperature, the green tapes were without deformation or cracking. After demolding and drying, the ceramic green tapes were debindered at $800-1000^{\circ} \mathrm{C}$ for 3 hours, at a ramp rate of $2-5^{\circ} \mathrm{C} / \mathrm{min}$. Final sintering was performed in a vacuum atmosphere $\left(10^{-5}-10^{-6} \mathrm{MPa}\right)$ at a temperature of $1700-1800^{\circ} \mathrm{C}$ for 3 hours, at a ramp rate of $2 \sim 10^{\circ} \mathrm{C} / \mathrm{min}$.

\subsection{Characterization for the slurries and ceramic wafers}

The rheological properties of the produced slurries were measured with a rotational control stress rheometer (TA Instrument AR2000 Rheometer, USA) in continuous shear mode in the region of $0.01 \mathrm{~s}^{-1}$ $1000 \mathrm{~s}^{-1}$, at $25^{\circ} \mathrm{C}$. The YAG green tapes were very flexible and could be bent and twisted freely. The surface and cross-sectional microstructure of the YAG green tapes and vacuum-sintered wafers were examined via scanning electron microscopy (SEM, Quanta 200F, FEI, USA). Phase compositions of YAG green body and vacuum-sintered transparent wafers were analyzed by X-ray diffraction (XRD, Bruker D2 Phaser, Germany) equipped with a $\mathrm{Cu}$ radiation $(\lambda=0.154 \mathrm{~nm})$ in the range of $2 \theta=10 \sim 75^{\circ}$. The in-line transmittance of the wafers was measured in the UV-VIS region using UV-VIS spectrometry (Perkin Elmer Lambda 950, Massachusetts, USA).

\section{Results and discussion}

\subsection{Rheological property}


The rheological behavior of the tape casting slurries was measured over shear rate range of $0.1-1000 \mathrm{~s}^{-1}$, the results of which are shown in Fig. 1(a). The measured YAG slurries displayed shear thinning behavior over the entire measured region, which is desirable for tape casting process. High viscosities were achieved at low shear rates, which could prevent particle flocculation and sedimentation. At high shear rate, the measured viscosities were relatively low, which is desirable in the actual forming step of tape casting. For example, the viscosity is less than $10 \mathrm{~Pa} \cdot \mathrm{s}$ at high shear rate $\left(>20 \mathrm{~s}^{-1}\right)$, which is useful to achieve homogeneous dispersion of the slurry system, and dimensional accuracy.

The shear thinning behavior of ceramic based suspensions used in tape casting could also be described by the equation below[34]:

$\tau=k(r)^{n}$

Where $\tau$ is the shear stress, $r$ is the shear rate and $n$ is a value unique to the material system which is less than one. Fig. 1 (b) shows the plot of the slip shear stress as a function of shear rate for YAG slip system. The value of $n$ can be calculated from the slope of curves in Fig. 1(b), which is less than one, consistent with Eq.(1). Hence, the shear stress curve verified the shear thinning behavior as expected.

\subsection{Tape casting of the YAG green wafer}

In the tape casting step, the casting was performed at a speed of $10-35 \mathrm{~cm} / \mathrm{min}$, similar to speeds reported in the literature for other water-based systems [14, 22, 24]. Without the addition of surfactant, all slurries wetted the Mylar carrier well and were "locked" onto the carrier to prevent the slip from receding and forming droplets. After drying for 2 hours on the Mylar carrier, the green tapes (Fig. 2, (a)) were easy to remove from the carrier film. No cracks, blisters or pinholes were observed in the green tape, and all had smooth surfaces. In addition, the tapes were smooth, flexible, and easy to handle (Fig.2 (b)). In conclusion, the binder ISOBAM can be used for aqueous tape casting systems to produce good quality tapes. 
Shown in Figure 3 are the fracture surfaces of YAG tape after debinding (Fig. 3(a)) and vacuum sintering (Fig. 3(b)). The particles in the fracture surfaces of the debindered YAG green tapes are distributed homogeneously without any agglomerates. However, there is neck-formation after the debinding process (Fig. 3 (a)). As shown in Figure 3 (b), the sintered YAG wafers show good optical properties and fully densified microstructure. The grains densified uniformly with grain size distribution of $1.5-5 \mu \mathrm{m}$, which was statistically calculated by Nano Measurer software. No differences in microstructure were observable between the casting and traverse direction. The fracture mode of the vacuum sintered YAG wafers appeared to be mainly transgranular for large grains, as well as minor intergranular for small grains within the grain size range of $1-3 \mu \mathrm{m}$. There were no obvious bubbles in the fracture surface of the sintered YAG ceramic. According to Archimedes' measurements, the relative densities of the green body and vacuum sintered body were measured with the results $\sim 54.5 \%$ for the green body and $99.5 \%$ for the vacuumsintered sample.

\subsection{Phase identification}

Figure 4 shows the phase compositions of the tape-casted green body after the debinding in air at 800$1000^{\circ} \mathrm{C}$ for 3 hours, and the YAG wafers sintered at $1700-1800^{\circ} \mathrm{C}$ for 3 hours. Kinsman et al.[35] reported that three phases, including YAM $\left(\mathrm{Y}_{4} \mathrm{Al}_{2} \mathrm{O}_{9}\right)$, YAP $\left(\mathrm{YAlO}_{3}\right)$, YAG $\left(\mathrm{Y}_{3} \mathrm{Al}_{5} \mathrm{O}_{12}\right)$, could be formed during the different temperature region for the $\mathrm{Al}_{2} \mathrm{O}_{3}-\mathrm{Y}_{2} \mathrm{O}_{3}$ system.

$$
\begin{array}{lr}
2 \mathrm{Y}_{2} \mathrm{O}_{3}+\mathrm{Al}_{2} \mathrm{O}_{3} \longrightarrow \mathrm{Y}_{4} \mathrm{Al}_{2} \mathrm{O}_{9} & 900^{\circ} \mathrm{C}-1100^{\circ} \mathrm{C} \\
\mathrm{Y}_{4} \mathrm{Al}_{2} \mathrm{O}_{9}+\mathrm{Al}_{2} \mathrm{O}_{3} \longrightarrow 4 \mathrm{YAlO}_{3} & 1100^{\circ} \mathrm{C}-1250^{\circ} \mathrm{C} \\
3 \mathrm{YAlO}_{3}+\mathrm{Al}_{2} \mathrm{O}_{3} \longrightarrow \mathrm{Y}_{3} \mathrm{Al}_{5} \mathrm{O}_{12} & 1400^{\circ} \mathrm{C}-1600^{\circ} \mathrm{C}
\end{array}
$$

In Fig.3, after the debinding at $800-1000^{\circ} \mathrm{C}$ for 3 hours, YAM was observed to exist with unreacted $\mathrm{Y}_{2} \mathrm{O}_{3}$ and $\mathrm{Al}_{2} \mathrm{O}_{3}$. After a vacuum sintering at $1700-1800{ }^{\circ} \mathrm{C}, \mathrm{YAG}$ is the only phase detected, indicating a complete reaction between $\mathrm{Y}_{2} \mathrm{O}_{3}$ and $\mathrm{Al}_{2} \mathrm{O}_{3}$. 
3.5 Optical transmittance of vacuum-sintered YAG wafer

A photo of a vacuum sintered sample with a thickness of $0.26 \mathrm{~mm}$ is shown in the inset of Figure 5 . The YAG chips also display excellent optical properties, and the in-line transmittance was measured to be about $82.6 \%$ at a wavelength of $800 \mathrm{~nm}$. These results verify that the ISOBAM tape casting system could be successfully used for the production of thin tapes with excellent preservation of optical properties.

\section{Conclusion}

Transparent YAG wafers were successfully processed by tape casting with ISOBAM as binder and the vacuum-sintering technique. Slurries produced with ISOBAM tape casting system show shear thinning behavior in the region of $0.1-1000 \mathrm{~s}^{-1}$. The final green tape is very flat, smooth, flexible, and easy to handle. The microstructure of the green tape is homogeneous without any observable agglomeration. The vacuum sintered YAG ceramic is uniform in both the casting and lateral direction with a grain size distribution of $1.5-5 \mu \mathrm{m}$ and transmittance of $82.6 \%$ at the wavelength of $800 \mathrm{~nm}$.

\section{Acknowledgments}

We gratefully acknowledge the Air Force Office of Scientific Research (AFOSR) (contract FA9550-14-1-0155) for funding and supporting this research.

\section{References}

[1] R. Mistler, D. Shanefield, R. Runk, G. Onoda, L. Hench, Ceramic Processing before firing. Ceramic Processing Before Firing (1978).

[2] T.P. Hyatt, Electronics: Tape casting, roll compaction. Am. Ceram. Soc. Bull. 74 (1995) 56-59.

[3] R. Moreno, The role of slip additives in tape-casting technology. I: Solvents and dispersants. Am. Ceram. Soc. Bull. 71 (1992) 1521-1531.

[4] K.R. Mikeska, W. Cannon, Non-aqueous dispersion properties of pure barium titanate for tape casting. Colloids Surf. 29 (1988) 305-321.

[5] D. Saha, R. Giri, K.K. Mistry, K. Sengupta, Magnesium chromate- $-\mathrm{TiO}_{2}$ spinel tape cast thick film as humidity sensor. Sens. Actuators B 107 (2005) 323-331.

[6] M. Wagner, A. Roosen, H. Oostra, R. Höppener, M. De Moya, Novel low voltage piezoactuators for high displacements. J. of Electroceram. 14 (2005) 231-238. 
[7] X. Ba, J. Li, Y. Pan, Y. Zeng, H. Kou, W. Liu, J. Liu, L. Wu, J. Guo, Comparison of aqueous-and nonaqueous-based tape casting for preparing YAG transparent ceramics. J. Alloys. Compd. 577 (2013) 228231.

[8] C. Gutierrez, R. Moreno, Tape casting of non-aqueous silicon nitride slips. J. Eur. Ceram. Soc. 20 (2000) 1527-1537.

[9] U. Paik, V.A. Hackley, S.-C. Choi, Y.-G. Jung, The effect of electrostatic repulsive forces on the stability of $\mathrm{BaTiO}_{3}$ particles suspended in non-aqueous media. Colloids Surf. A: Physicochemical and Engineering Aspects 135 (1998) 77-88.

[10] N. Pinna, G. Garnweitner, M. Antonietti, M. Niederberger, Non-aqueous synthesis of high-purity metal oxide nanopowders using an ether elimination process. Adv. Mater. 16 (2004) 2196-2200.

[11] A. Ceylan, E. Suvaci, H. Mandal, Role of organic additives on non-aqueous tape casting of SiAION ceramics. J. Eur. Ceram. Soc. 31 (2011) 167-173.

[12] Y. Qiao, Y. Liu, A. Liu, Y. Wang, Boron carbide green sheet processed by environmental friendly nonaqueous tape casting. Ceram. Int. 38 (2012) 2319-2324.

[13] L. Nikzad, A. Mirhabibi, M. Vaezi, J. Javadpoor, Tape casting of graphite in non-aqueous media. Mater. Des. 30 (2009) 346-352.

[14] P.R. Nahass, W.E., Pober, R. L., Bowen, H. K., A comparison of aqueous and non-aqueous slurries for tape-casting and dimensional stability in green tapes, in: R.P. K.M. Nair, R.C. Buchanan (Ed.) Materials and processes for microelectronic systems, In Ceramic transactions, The American Ceramic Society, 1990, pp. 355-364.

[15] R. Mistler, The principles of tape casting and tape casting applications, Ceramic processing, Springer, 1995, pp. 147-173.

[16] R.C. Chiu, T. Garino, M. Cima, Drying of granular ceramic films: I, effect of processing variables on cracking behavior. J. Am. Ceram. Soc. 76 (1993) 2257-2264.

[17] R.C. Chiu, M.J. Cima, Drying of granular ceramic films: II, drying stress and saturation uniformity. J. Am. Ceram. Soc. 76 (1993) 2769-2777.

[18] J. Schuetz, I. Khoury, R. DiChiara, Water-based binder for tape casting. Ceram. Ind. 129 (1987) 42.

[19] C. Pagnoux, T. Chartier, M. de F Granja, F. Doreau, J. Ferreira, J. Baumard, Aqueous suspensions for tape-casting based on acrylic binders. J. Eur. Ceram. Soc. 18 (1998) 241-247.

[20] L. Wang, G. Tang, Z.-K. Xu, Preparation and electrical properties of multilayer ZnO varistors with water-based tape casting. Ceram. Int. 35 (2009) 487-492.

[21] K. Burnfield, B. Peterson, Cellulose ethers in tape casting formulation. Ceram. Trans. 26 (1991) 191196.

[22] T. Chartier, A. Bruneau, Aqueous tape casting of alumina substrates. J. Eur. Ceram. Soc. 12 (1993) 243-247.

[23] L.H. Luo, Y. Lang, Z.Z. Huang, L. Cheng, J.J. Shi, Fabrication of YSZ film by aqueous tape casting using PVA-B1070 cobinder for IT-SOFC. Key. Eng. Mater. 434 (2010) 735-738.

[24] A. Kristoffersson, E. Carlström, Tape casting of alumina in water with an acrylic latex binder. J. Eur. Ceram. Soc. 17 (1997) 289-297.

[25] F. Snijkers, A. De Wilde, S. Mullens, J. Luyten, Aqueous tape casting of yttria stabilised zirconia using natural product binder. J. Eur. Ceram. Soc. 24 (2004) 1107-1110.

[26] G.W.S. M. D. Sacks, The electronics division fall meeting on multilayer ceramic devices, Am. Ceram. Soc., 1986.

[27] J.-H. Jean, S.-F. Yeh, C.-J. Chen, Adsorption of poly (vinyl butyral) in nonaqueous ferrite suspensions. J. Mater. Res. 12 (1997) 1062-1068.

[28] Y. Yang, S. Shimai, Y. Sun, M. Dong, H. Kamiya, S. Wang, Fabrication of porous $\mathrm{Al}_{2} \mathrm{O}_{3}$ ceramics by rapid gelation and mechanical foaming. J. Mater. Res. 28 (2013) 2012-2016. 
[29] Y. Yang, S. Shimai, S. Wang, Room-temperature gelcasting of alumina with a water-soluble copolymer. J. Mater. Res. 28 (2013) 1512-1516.

[30] Y. Yang, Y. Wu, New gelling systems to fabricate complex-shaped transparent ceramics, SPIE Defense, Security, and Sensing, International Society for Optics and Photonics2013, pp. 87080D-87088.

[31] S. Shimai, Y. Yang, S. Wang, H. Kamiya, Spontaneous gelcasting of translucent alumina ceramics. Opt. Mater. Express 3 (2013) 1000-1006.

[32] Y. Sun, S. Shimai, X. Peng, M. Dong, H. Kamiya, S. Wang, A method for gelcasting high-strength alumina ceramics with low shrinkage. J. Mater. Res. 29 (2014) 247-251.

[33] Y. Sun, S. Shimai, X. Peng, G. Zhou, H. Kamiya, S. Wang, Fabrication of transparent $\mathrm{Y}_{2} \mathrm{O}_{3}$ ceramics via aqueous gelcasting. Ceram. Int. (2014).

[34] M.N. Rahaman, Ceramic processing, CRC Press, 2006.

[35] K. M. Kinsman, J. McKittrick, E. Sluzky, and K. Hesse, Phase developmentand luminescence in chromium-doped yttrium aluminum garnet (yag:cr) phosphors, J. Am. Ceram. Soc., 77 [1994] 2866-2872 


\section{Figure captions}

Fig. 1 Rheology property as a function of shear rate (a) viscosity; (b) shear stress

Fig. 2 Photographs of the YAG green tape after demolding at room temperature

Fig. 3 Microstructure of fracture surfaces of YAG tape after (a) debinding at $800-1000^{\circ} \mathrm{C}$ for 3 hours and (b) vacuum sintering at $1700-1800^{\circ} \mathrm{C}$ for 3 hours

Fig. 4 X-ray diffraction pattern of YAG green body $\left(800-1000^{\circ} \mathrm{C}, 3\right.$ hours $)$ and vacuum-sintered wafer $\left(1700-1800^{\circ} \mathrm{C}, 3\right.$ hours $)$

Fig. 5 Transmittance of vacuum-sintered $\left(1700-1800^{\circ} \mathrm{C}, 3 \mathrm{~h}\right) \mathrm{YAG}$ chips formed by aqueous tape casting methods using ISOBAM as binder. 
FIGURES

figure 1

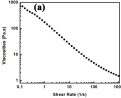

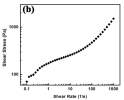


figure 2

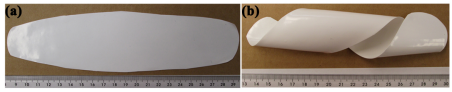




\section{figure 3}

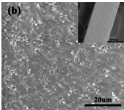


figure 4

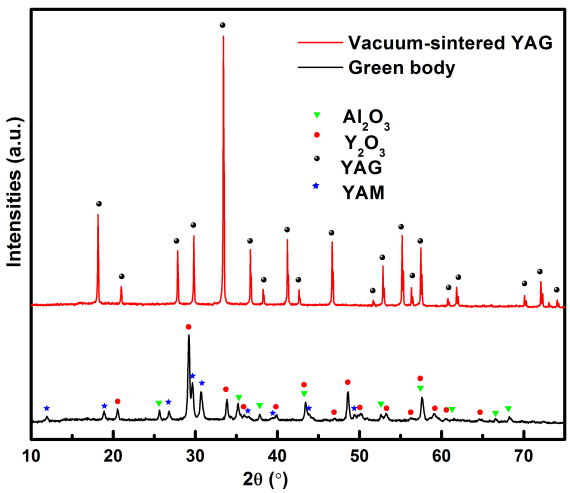




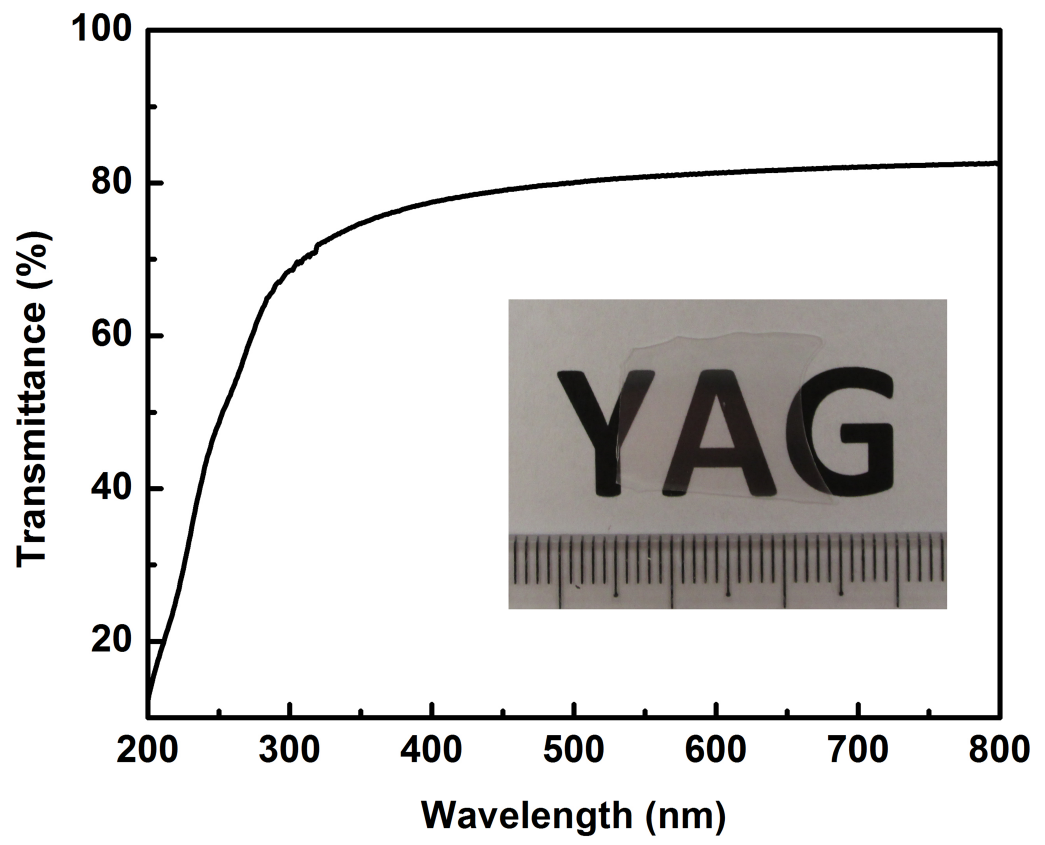

